\title{
Ética y empleados públicos *
}

\section{Jaime Rodríguez-Arana Muñoz **}

\section{Marco actual de la ética pública}

Es para mí un placer participar en este encuentro organizado por la Fundación Fernando de los Ríos sobre el Estatuto de la función pública con unas reflexiones sobre la Ética en el ámbito de las Administraciones Públicas, ya que el compromiso de los sindicatos con la defensa no sólo de los intereses de los trabajadores a los que representan sino de los valores que sustentan a las organizaciones públicas a las que sirven, hacen de la acción sindical un elemento esencial de transmisión y de promoción de estos valores, en beneficio de toda nuestra sociedad.

Hablar de ética del servicio público, o del trabajo de los empleados públicos desde una perspectiva ética, no es hoy solamente una moda, sino que supone hacer referencia a unos de los pilares de las reformas administrativas que están en marcha en todo el mundo, como trataré de exponer más adelante.

Pues bien, hemos de iniciar el análisis de esta cuestión partiendo de la realidad más próxima, para comprobar que, en nuestro país, la ética de las actuaciones del poder público y de sus agentes - sean éstos políticos o empleados públicos- ocupa un lugar predominante en el debate social. A la luz de este debate $-y$, en especial, de su reflejo en los medios de comunicación- parecen surgir dudas sobre la solidez moral de nuestra vida pública. Estas dudas son percibidas por los empleados públicos como un ataque indiscriminado e injusto contra el trabajo y la dedicación de todos aquellos que tienen como tarea el servir a la sociedad. Y ello es, además, un importante factor de desmo- tivación de los servidores públicos, que ven cómo a menudo su trabajo no sólo no es suficientemente valorado, sino que sobre él se arrojan, desde distintos ámbitos, serios interrogantes respecto de su honestidad.

Creo que esta valoración ética de la Administración, o, más bien, esta percepción social de nuestra ética, no es generalizada, pero sí está lo suficientemente extendida como para preocuparnos por ella.

Debemos comenzar por senalar, no obstante, que la Administración no es más que una parte de la sociedad a la que sirve. Por ello, sobre la Administración se reflejan, forzosamente, los valores que imperan en el entorno social. Así, el propio ambiente social de nuestros días, en el que se potencia un consumo salvaje o la valoración de las personas en función de su éxito económico, quizá sea el caldo de cultivo adecuado para la proliferación de una cultura en la que los valores éticos encuentran dificultades, a menudo difíciles de salvar, para abrirse paso. En este contexto, es dificil concebir un intento de moralización de la vida pública ajeno al resurgimiento de dichos valores en la sociedad en general y en las personas que la componen en particular.

Paralelamente y como consecuencia de la situación descrita, en la sociedad parece haber prendido la conciencia de que es necesario regenerar la democracia. Y, para ello, nada mejor que mirar a los principios que deberian inspirarla en todo momento.

En este marco, como ha recordado Tuseu, reviste especial importancia la exigencia de un nivel ético elevado, lo que no se traduce sólo en la existencia de instrumentos que regulen la conducta sino, sobre todo, de transparencia en cada uno de los aspectos en que la vida privada se encuentra con la pública. 
Por tanto, si la Ética es, o debe ser, una condición intrínseca a la democracia, el número de actuaciones contrarias a la ética que se producen en estos tiempos nos invita a buscar fórmulas para colocar la exigencia ética en el lugar que debe ocupar. Pero para ello hay que articular sistemas educativos que formen en los valores de la libertad y de la democracia en un ambiente de humanización de la realidad. Algo, que, en mi opinión, no se ha tratado suficientemente, o se ha tratado muy superficialmente.

Quizá, en el fondo, lo que se está perdiendo son los hábitos vitales de la democracia que, como dice John Dever, se resumen en ala capacidad de perseguir un argumento, captar el punto de vista del otro, extender las fronteras de nuestra comprensión y debatir objetivos alternativos", pero eso sería objeto de otro debate.

Pues bien, la preocupación colectiva por la conducta pública de la que hablaba no sólo se debe, en nuestro caso, a las consecuencias de un largo período de escándalos políticos, que han alcanzado a los más altos estamentos del poder, con la consiguiente merma de legitimidad para muchos de ellos.

En mi opinión, el proceso de crisis del Estado del Bienestar en el que llevamos ya anclados, de forma más o menos consciente, un buen número de años, ha contribuido a agravar esta situación.

Durante estos últimos años, es evidente que el campo de la discrecionalidad ha crecido desproporcionadamente, al tiempo que los Estados, acuciados por la necesidad de obtener logros y eficacia se alejaban —huían", como se ha dicho- de la sujeción a determinadas normas de actuación que encierran, no lo olvidemos, garantías para los ciudadanos. Al mismo tiempo, la confusión de intereses públicos o privados o de grupo ha hecho acto de presencia con inusitada fuerza y, lo que es peor, los poderes públicos, con relativa frecuencia, se han convertido en instituciones que entran también al juego de los grupos de interés. Por tanto, en el fondo de la preocupación ciudadana a la que me refería al inicio subyace, en realidad, una, quizá amarga, toma de conciencia sobre el papel del Estado en la vida social —omnímodo y siempre presente- y sobre las consecuencias de este papel para los derechos fundamentales.

¿Es correcto, entonces, asociar el excesivo intervencionismo del Estado que hemos conocido con la merma o el descuido de los valores éticos? En mi opinión, sí. Y lo es, sencillamente, porque un Estado que interviene en todos los recodos de la vida social, alimenta la creación de grupos de interés que desean sacar beneficios directos de los poderes públicos. No olvidemos que, como señala el profesor ARANGUREN, toda comupción pública ha de tener su correspondencia en los intereses privados.

Se puede argumentar que la corrupción, en cuanto que utilización de potestades públicas para la satisfacción de intereses puramente personales, es un fenómeno que siempre se ha producido en la sociedad porque, como es bien sabido, en todos los colectivos siempre han existido personas que no han seguido las reglas de juego. Ahora bien, debemos hacer hincapié en el hecho de que, en relación con los servidores públicos, la comupción supone el más grave atentado contra la misma esencia del servicio público, en la medida que supone que el responsable político o el empleado público traiciona el sentido de la gestión de intereses colectivos. Se produce, por tanto, una conversión del interés público en interés personal. Ésa es su malicia y su peligro.

No creo que sea preciso señalar, porque ustedes lo saben mejor que nadie, que la gran mayoría de los servidores públicos realizan sus tareas correctamente y se guían por criterios éticos. El problema surge de la necesidad de reaccionar, desde el aparato público - y desde la dimensión personal- contra quienes se apartan de la ética, vulneran el compromiso de defensa de los intereses generales en el que todos estamos implicados y, además, hacen llegar a la sociedad una percepción que pone en duda la honestidad de quienes la sirven.

Frente a estas situaciones, la reacción debe discurrir por vías jurídicas y, al mismo tiempo, a través de los instrumentos internos que la propia Administración debe promover, en los que queden muy claros los fines del servicio público y la "anormalidad" del uso de los poderes públicos en exclusivo beneficio personal. Y hago ya una primera mención, sobre la que volveré, al papel decisivo que los sindicatos deben jugar, en mi opinión, en la puesta en funcionamiento de estos instrumentos de garantía ética en las distintas organizaciones públicas.

Como decía, la corrupción atenta contra los valores éticos del servicio público en cuanto que implica la utilización de potestades públicas para el exclusivo provecho personal. Supone, pues, la desnaturalización de la función constitucional de la Administración pública, que consiste en servir con objetividad los intereses generales. Por ello, la mera existencia de estas situaciones genera un compromiso al que debemos atender entre todos. El propiciar que, a partir de ahora, toda reforma administrativa tenga presente el fin último del Estado frente a los fines propios de las organizaciones: el servicio público y la plena realización de los derechos fundamentales de los ciudadanos. Sólo así superaremos el desfasado debate entre legalidad y eficacia en la dirección correcta: la que nos lleve a un mayor humanismo en las relaciones de la Administración con los ciudadanos, ya que, como afirma CROZIER:

la Reforma Administrativa es un proceso de mejora mucho más centrado en los valores y en la inteligencia que en la estructura y la técnica; mucho más relacionado con los fines que con los medios. 


\section{2. Ética y empleados públicos}

Creo que nos corresponde ahora reflexionar sobre las especiales circunstancias que, desde el punto de vista de la Ética, rodean la actividad de los empleados públicos, cuya misión profesional —no lo olvidemos- es servir al interés público y al bien común.

Para ello, debemos retomar nuestra reflexión inicial sobre el papel del Estado frente a la sociedad, para asumir que nos encontramos en un contexto de cambio. El llamado Estado Providencia está dejando paso a un nuevo Estado que, inspirándose en principios como el de subsidiariedad, asume la obligación de redimensionarse, adecuando el tamaño del sector público a las prestaciones esenciales que debe garantizar y propiciando la participación, cada vez más activa, de los ciudadanos y grupos sociales en la fijación de los objetivos de bienestar.

Efectivamente, el ciudadano está llamado a configurar los intereses públicos y, por tanto, el interés general porque en el sistema democrático todos son, o deben ser, responsables de los intereses generales. Pero la participación es posible cuando el Estado es sensible a las iniciativas de los individuos, cuando se estimula, cuando se promueve, cuando se desea formar personas que se tomen en serio su papel en la promoción del interés colectivo. Hoy en día, es cada vez más urgente recordar que concuerda con la dignidad humana el derecho a tomar parte activa en la vida pública y a contribuir al bien común. La participación debe ser, por tanto, un presupuesto y, a la.vez, un condicionante de la actividad de los poderes públicos:

Por otra parte, en el contexto que venimos describiendo, los empleados públicos se encuentran - nos encontramos- en medio de una tensión que nos lleva a asumir las funciones y responsabilidades que la sociedad demanda, contando con unos recursos cada vez más limitados. Así, por ejemplo, las disponibilidades presupuestarias, siempre escasas, no favorecen un reparto generoso de las cargas de trabajo y dificultan la motivación mediante incentivos económicos.

Paralelamente, los instrumentos con que cuenta la gestión pública se han ido adaptando también a estas circunstancias, de forma que, en estos momentos, son más flexibles. Pero la búsqueda de la eficacia y la eficiencia por encima de todo se ha dejado por el camino buena parte del rigor normativo y procedimental que construyó el Estado de Derecho. Las consecuencias de ello se dejan sentir, por ejemplo, en el aumento de los poderes de apreciación y, en definitiva, del uso de la discrecionalidad en la toma de decisiones administrativas.
Estas nuevas formas de gestión también apuestan decididamente por la descentralización de los poderes decisorios. Y esto, que es bueno como principio de acercamiento al ciudadano, supone también, en muchos casos, diluir las responsabilidades por las consecuencias de los actos administrativos, e, incluso, encubrir mejor las conductas incorrectas o no éticas. La propuesta de Administración Única que defendemos desde el Gobiemo, trata de poner coto a estas situaciones.

Para completar este cuadro de condicionantes actuales de la Ética administrativa, la omnipresencia del Estado en la Economía -que hemos heredado del intervencionismo- y los nuevos instrumentos de gestión que adoptan formas privadas (llámense agencias, entes, empresas, etc.) han creado una red de interconexiones entre el sector público y los intereses privados que, siendo a menudo necesarias para cumplir sus objetivos, pueden suponer un cierto riesgo de que los gestores públicos pierdan de vista, en algún momento, el fin al que sirven.

Lo cierto es que estas circunstancias, por sí solas, no deberían crear problemas de conductas no éticas en la Administración y el Sector Público. Sin embargo, debemos valorar hasta qué punto las mismas están multiplicando las ocasiones en las que se sitúa a los servidores públicos, frente a poderosos conflictos de intereses, que pueden entrañar eventuales riesgos.

Por tanto, si las circunstancias nos enfrentan a muchos riesgos, es preciso dar la importancia que realmente tiene al respeto a los principios éticos y la defensa de los valores que los inspiran.

Si a todo lo expuesto sumamos el desfase entre los sistemas tradicionales de control de la actividad administrativa - los regímenes disciplinarios, por ejemplo- y las funciones y objetivos que la sociedad nos exige, veremos que la necesidad acuciante de que la Ética cobre protagonismo en la Administración Pública no es sólo un problema de recuperar valores que han caído en desuso, sino que es una prioridad a la hora de acometer cualquier reforma que pretenda conseguir que el Estado sirva adecuadamente a la sociedad.

Asumida, pues, la premisa de la importancia que tiene la Ética en el Servicio Público, en un contexto de cambio como en el que nos encontramos, debemos abordar las consecuencias prácticas que este hecho puede tener.

Un reciente documento de la OCDE, de 1996, en el que se analizan los intentos de distintos países de poner en marcha sistemas de garantía de las conductas éticas en el Sector Público, gira en torno a la necesidad de dotar al Estado de una anfraestructura de la Éticaw. Este término englobaría al conjunto de instrumentos, procedimientos y normas destinados a reforzar las conductas adecuadas y evitar, identificar y corregir las conductas indeseables desde el punto de vista ético. 
La OCDE hace referencia a la gestión ética de las conductas públicas, como el instrumento que nos permita superar los riesgos y las contradicciones que ya hemos identificado, entre los sistemas tradicionales de control de la actividad de los servidores públicos, las funciones que éstos tienen hoy encomendadas y los valores que estamos obligados a preservar. Por tanto, es preciso instrumentar los medios para promover y controlar el respeto no sólo a las normas penales y disciplinarias, que regulan las conductas antijurídicas, sino a los principios y valores que sustentan el servicio público.

Cualquier reforma en este sentido debe tener en cuenta la experiencia de otros países. Algunos de ellos han optado por regular esta materia de forma independiente a otras cuestiones organizativas, dándole así una importancia preeminente (éste es el caso de los países anglosajones, Estados Unidos y Gran Bretaña, además de, por ejemplo, Noruega y Holanda). Otros han optado por revisar la gestión de la ética en el contexto de reformas globales de la Función Pública (Australia o Nueva Zelanda) o de programas de modernización del Sector Público en su conjunto (como Méjico o Portugal).

En este sentido, es interesante comprobar cómo existe una gran homogeneidad de los valores que integran la Ética del Servicio Público entre todos los países que afrontan su regulación, hasta el punto que podríamos hablar de unos valores universales de la Ética Pública.

Así, la lealtad a los principios constitucionales, la absoluta desvinculación de los intereses personales y económicos respecto del trabajo al servicio del Estado, la honestidad, el respeto y la defensa de los bienes y el patrimonio público, o el trato adecuado a los ciudadanos, están presentes, de una u otra forma, en todas las normas sobre Ética de todo el Mundo.

Pero, para promover estos principios y su cumplimiento, habrá que atender a las condiciones particulares de cada cultura administrativa. En mi opinión, en el caso de España, la regulación de los instrumentos al servicio de la Ética Pública debería incluir los siguientes aspectos:

a) Una definición clara de las relaciones entre política y actividad administrativa, que permita garantizar la independencia del trabajo de los funcionarios públicos y, a la vez, delimitar claramente, en cada caso, sus responsabilidades de las responsabilidades de los políticos que les dirigen, en el buen hacer de la Administración.

b) Es preciso definir, también, los principios que deben regir la actuación de los servidores públicos e, incluso, tipificar - con el grado de concreción que resulte posiblelas conductas que se separen o entren en clara contradicción con esos principios. En relación con esta definición, creo que la codificación de la ética pública es el medio más adecuado para determinar su contenido, di- fundirlo entre sus destinatarios y, finalmente, garantizar el respeto a sus principios.

c) También es necesario dotar a los servidores públicos de la información y los conocimientos suficientes para afrontar situaciones de conflicto ético con responsabilidad. En este sentido, la formación en materia de ética pública deberá ocupar un lugar primordial en los programas formativos para empleados públicos, especialmente para los de nuevo ingreso.

d) Es preciso, también, establecer los medios adecuados para coordinar esta gestión de la ética en los distintos ámbitos administrativos, de forma que se promueva la difusión y el respeto a los principios y normas éticas con que se dote la Administración.

e) Un marco jurídico adecuado, unas condiciones de trabajo favorables en el sector público y, por último, una sociedad civil activa, vigilante y participativa, deberán completar la implantación de esta infraestructura ética.

Permítanme completar mi exposición deteniéndome en dos de estos puntos, que considero de especial interés y sobre los que reclamo sus opiniones, como representantes de los empleados públicos y factores decisivos de toda reforma que pueda emprenderse en la dirección que venimos comentando.

\subsection{Codificación}

En primer lugar, en relación con la definición de principios y la adecuada codificación ética de la actividad administrativa, quizá es preciso comenzar preguntándonos hasta qué punto esta fijación de los principios éticos en un documento normativo no les priva del carácter supra legal que estos principios deben tener.

Pero, más allá de las relaciones entre Ética y Derecho-que constituyen, por sí mismas, un interesante debate-creo que a los empleados públicos y a los ciudadanos nos conviene que estén convenientemente definidas las vulneraciones de la Ética Pública, ya que no todo en servicio público puede reducirse a derechos y, más aún, no pocas veces vemos que la legalidad es perfectamente compatible con conductas contrarias a la ética.

Debemos partir, pues, de una visión de la codificación ética como complemento de la tipificación legal de las conductas y como cláusula de garantía, respecto de los conflictos humanos que se suscitan en el ámbito de la actividad administrativa y a los que el Derecho no alcanza a dar una respuesta adecuada.

A partir de aquí, pienso que la codificación ética debe comenzar por contar con el máximo nivel de participación de sus destinatarios, los empleados públicos. Y es que, si bien es cier- 
to que hoy podemos atribuir a los valores de la ética del servicio público, como hemos dicho, un carácter universal, también lo es que éstos deben ser asumidos e interiorizados por aquellos para quienes van a servir de guía en su quehacer diario. Y ello, porque, como señala igualmente ARANGUREN en relación con la función que tiene la Ética en la potenciación de lo público:

en la práctica, la forma más poderosa de hacer esta tendencia real es que cada miembro de la burocracia la haya interiorizado de alguna manera.

De esta forma, se garantizará su eficacia al tiempo que se evitará que el desconocimiento o la falta de una conciencia clara sobre el alcance de la Ética del Servicio Público, ralenticen la acción de unos funcionarios a los que el miedo a cometer errores y someterse a nuevos controles y, en definitiva, les dificulte desarrollar su trabajo con normalidad, lo cual carecería de sentido.

En mi opinión, la codificación de la Ética Pública deberá cumplir una doble misión, como forma de expresar las aspiraciones de la sociedad respecto de la acción pública y, a la vez, como medio de control de la adecuación de las conductas a los principios del servicio público. Para ello, se debería:

a) Enunciar los valores que presiden la actividad de servicio público.

b) Determinar el grado de responsabilidad que el cumplimiento de esos valores representa para los servidores públicos (políticos, empleados públicos, ciudadanos que colaboren con la Administración, etc.).

c) Recoger una lista de las obligaciones de actuar y límites que representan esos principios en la actividad pública.

d) Finalmente, definir los medios para alertar a la Administración y los ciudadanos de la aparición de conductas no éticas y corregir éstas.

Por otro lado, la codificación deberá ser lo bastante general como para contemplar la mayoría de las conductas públicas en las que puede surgir un conflicto ético, pero sin descender a un detalle excesivo en la tipificación, que lo haría escasamente operativo. En este sentido, me parece adecuada la propuesta del documento de la OCDE al que me refería antes, de completar un Código General de Ética Pública, de aplicación en todas las Administraciones de nuestro país, con normas de éticas complementarias por sectores, que hagan incidencia en aspectos más concretos $y$, por tanto, tipificables de la actividad administrativa (trabajo cara al público, manejo de bienes públicos, especial vinculación de determinados funcionarios con sectores privados - por su perfil académico o profesional, por ejemplo- etc.).

Por último, este carácter generalista de la codificación ética, trae a colación la cuestión - aún abierta - de su forma o base normativa. En este sentido, debe tenerse en cuenta que la regu- lación legal de esta materia, permitiría fijar adecuadamente sus principios, si bien puede suponer una cierta merma de flexibilidad respecto de futuras modificaciones que la adapten a la realidad cambiante. El futuro Estatuto de la Función Pública, que el Gobiemo va a presentar a las Cortes el año próximo y que es objeto de la preocupación de ustedes en estas jomadas, puede ser el acomodo adecuado para recoger los aspectos fundamentales de la codificación ética en España, aunque su desarrollo posterior sea objeto de otras normas específicas.

En todo caso, el contenido de un futuro Código Ético de las Administraciones Públicas debe completarse tras una reflexión abierta para la que, desde el Ministerio de Administraciones Públicas, solicitamos su participación como representantes de los servidores públicos.

\subsection{Formación}

Permitanme, para terminar, hacer referencia a otro de los instrumentos del desarrollo de la ética en el ámbito público, al que me refería, diciendo que es preciso dotar a los servidores públicos de la información y los conocimientos suficientes para afrontar situaciones de conflicto ético con responsabilidad.

La formación en materia de ética pública es, quizá, el factor más importante para garantizar que nuestras organizaciones públicas inspiren su actividad diaria en los valores del servicio a nuestra sociedad. Por ello, los valores éticos del servicio público deberán ocupar un lugar primordial en los programas formativos para empleados públicos.

Es evidente que, también aquí, la formación de los empleados públicos debería ser una mera prolongación de su formación personal, si bien ahora en relación con su profesión al servicio de la sociedad. Y, en cualquier caso, la formación ética dirigida a los empleados públicos debería tener un fuerte contenido práctico. Se trata, en definitiva, de proporcionar principios y facilitar que, en el caso concreto, se pueda identificar el criterio más ajustado a los intereses públicos y a los derechos humanos en un contexto de búsqueda del bien común. Es decir, los programas de educación o formación en esta materia deben capacitar a los empleados públicos para la resolución de muchos problemas.

Estudios previos realizados en el ámbito de los centros de formación de la Administración General del Estado sobre la transmisión de los valores éticos del servicio público —en el marco del Instituto Nacional de Administración Pública (INAP) y de la Escuela de Hacienda Pública (EHP) - han puesto de relieve, también, la importancia de prestar especial atención a los empleados públicos de nuevo ingreso que «pueden así actuar como elementos transmisores de estos valores en el seno de sus organizaciones de destinon. 
En este sentido, la formación ética de los empleados públicos tiene un aspecto más positivo que debe subrayarse: la realización de los valores del servicio público introduce un evidente factor impulsor de motivación en la función pública y permite recordar la justificación constitucional de la función pública: servir con objetividad a los intereses generales haciendo efectivo el bien común.

En cuanto a la metodología, los estudios a los que me he referido señalan que la Ética pública debe integrarse en el marco de los distintos planes de estudios, de forma que las enseñanzas de los centros o programas de formación de empleados públicos siempre tengan presentes contenidos de la Ética pública. Estoy sustancialmente de acuerdo con esta idea y, por ello, el plan de formación del Ministerio de Administraciones Públicas para 1997, que estamos diseñando, va a incluir cursos de ética para nuestros empleados públicos y, en este caso, ha sido una iniciativa de los representantes sindicales la que los ha puesto en marcha.

Sin embargo, mientras esto no sea así, con carácter generalizado, no encuentro mayor problema en que se preparen unos cursos monográficos sobre Etica pública a los que puedan acceder los empleados públicos de los distintos departamentos u organizaciones. En el ámbito de la Administración General del Estado, el INAP está ya preparando la convocatoria de un curso, que se publicará en fechas próximas, y que comience a impartirse, probablemente, en el primer trimestre de 1997.

Quiero, también en este caso, solicitar la colaboración de ustedes en la definición de contenidos éticos en los programas de formación de empleados públicos, en cuyo diseño participan activamente, al tiempo que les ofrezco la colaboración del Ministerio de Administraciones Públicas en este empeño. Insisto en que ello redundará, siempre, en beneficio de los ciudadanos a los que servimos y de los propios empleados públicos, a los que la formación ética debe facilitar instrumentos adecuados para evaluar situaciones, resolver las contradicciones que se presentan en el día a día del trabajo público de la mejor forma posible $y$, en definitiva, realizar su tarea de forma más consciente y participativa.

Termino, por tanto, trasladándoles a ustedes, una vez más, la invitación para participar en el proceso de definición y promoción de los principios de la ética pública en nuestro país. Como habrán podido comprobar a lo largo de mi exposición, la Ética Pública en España es hoy, aún, una cuestión abierta al debate. Un debate que nos deberá llevar, en todo caso, a lograr que el papel del Estado en este fin de siglo se asiente sobre unas bases más sólidas que las actuales. Y éstas no pueden tener su apoyo, como hasta ahora, sólo sobre los tres pilares conocidos - las tres «Es- Economía, Eficacia y Eficiencia. A ellos debe unirse, cuanto antes, una nueva ‘E», un cuarto pilar: la Ética.

Notas

\footnotetext{
- Texto de la conferencia impartida por su autor en Cáceres, el 15 de noviembre de 1996, en el marco de unas Jornadas sobre el estudio del Estatuto de la Función Pública, organizadas por la Fundación Femando de los Ríos.

- Catedrático de Derecho Administrativo. Subsecretario de Administraciones Públicas
} 